\title{
The Effect of Al Content on Tensile and Fatigue Properties of Solution-Treated and Quenched Ti-13Cr-1Fe Alloys
}

\author{
Michiharu Ogawa ${ }^{1}$, Tetsuya Shimizu ${ }^{1}$, Toshiharu Noda ${ }^{1}$ and Masahiko Ikeda ${ }^{2}$ \\ ${ }^{1}$ Research \& Development Lab., Daido Steel Co., Ltd., Nagoya 457-8545, Japan \\ ${ }^{2}$ Department of Materials Science and Engineering, Faculty of Engineering, FSC, Kansai University, Suita 564-8680, Japan
}

\begin{abstract}
The effect of $\mathrm{Al}$ content on tensile and fatigue properties of $\mathrm{Ti}-13 \mathrm{Cr}-1 \mathrm{Fe}$ alloys was investigated by measurement of electrical resistivity and Vickers hardness, X-ray diffractometry (XRD), and tensile and fatigue tests. Only $\beta$ reflection was detected by XRD in all alloys quenched from $1173 \mathrm{~K}$. Resistivity at room and liquid nitrogen temperatures increased monotonically with Al content. Vickers hardness slightly increased with $\mathrm{Al}$ content up to 4.5 mass $\%$. In 6.0 mass $\% \mathrm{Al}$, the Vickers hardness increased dramatically. In 0 mass $\% \mathrm{Al}$ and $3.0 \mathrm{mass} \% \mathrm{Al}$, the tensile strength $\left(\sigma_{\mathrm{B}}\right)$ and $0.2 \%$ proof stress $\left(\sigma_{0.2}\right)$ remained almost constant. Above 4.5 mass $\%, \sigma_{\mathrm{B}}$ and $\sigma_{0.2}$ increased with increasing Al content. S-N curves in high cycle fatigue test of 0 mass $\% \mathrm{Al}$ and 3.0 mass $\% \mathrm{Al}$ showed almost the same behavior. The stress at $10^{7}$ cycles, i.e. the fatigue strength, was around $460 \mathrm{MPa}$. [doi:10.2320/matertrans.48.390]
\end{abstract}

(Received September 29, 2006; Accepted January 22, 2007; Published February 25, 2007)

Keywords: Titanium-chromium-iron-aluminum alloy, healthcare and welfare goods, electrical resistivity, tensile strength, fatigue, athermal $\omega$

\section{Introduction}

In countries like the UK, France, and Japan, the elderly population increases every year. ${ }^{1)}$ In particular, in Japan, the proportion of the elderly population surpassed $20 \%$ in 2005. Thus, it is very important to develop welfare goods with higher performance, such as wheelchairs, for elders. This requires the development of new materials, especially metallic materials having higher performance, higher specific strength, higher corrosion resistance, good biocompatibility ${ }^{2)}$ and reasonable cost. One attractive class of metallic materials is titanium and its alloys owing to their high specific strength and corrosion resistance and good biocompatibility. Unfortunately, their high cost constitutes a barrier to the use of titanium alloys in welfare goods. Thus, it is important to develop reasonably low-cost titanium alloys. To lower the cost $\beta$ titanium alloys, low-cost alloying elements such as $\mathrm{Cr}$ and $\mathrm{Fe}$, and 2nd grade sponge titanium, have been employed. So far, Ti-13 mass \% Cr-1 mass \%Fe alloy has been developed as a promising candidate alloy substituting for conventional $\beta$ titanium alloys. ${ }^{3)}$ Unfortunately, it has high possibility that this system alloys become brittle through isothermal $\omega$ precipitation. ${ }^{4)}$ It is well-known that $\mathrm{Al}$ addition to $\beta$ titanium alloys suppresses isothermal $\omega$ precipitation and have an effect of solution-hardening. Therefore, it is important to investigate that the influence of $\mathrm{Al}$ content on mechanical properties of Ti-Cr-Fe system.

In the present study, the effect of $\mathrm{Al}$ addition on the tensile and fatigue properties of $\mathrm{Ti}-13 \mathrm{Cr}-1 \mathrm{Fe}$ alloys quenched from a temperature within the $\beta$ phase region were investigated to compare the mechanical properties of the present alloys with those of commercial $\beta$ titanium alloys.

\section{Experimental Procedures}

The alloys were prepared by a levitation furnace using sponge titanium, chromium, ferro-chromium alloy and aluminum as raw materials. The roughly $10 \mathrm{~kg}$ ingots obtained were hot-forged at about $1323 \mathrm{~K}$ into about $20 \mathrm{~mm}$
Table 1 Alloy marks and chemical compositions of alloys used in this study.

\begin{tabular}{ccccccc}
\hline \multirow{2}{*}{ Alloy marks } & \multicolumn{6}{c}{ Chemical composition (mass\%) } \\
\cline { 2 - 7 } & $\mathrm{Cr}$ & $\mathrm{Fe}$ & $\mathrm{Al}$ & $\mathrm{C}$ & $\mathrm{N}$ & $\mathrm{O}$ \\
\hline 0Al & 12.6 & 1.21 & $<0.01$ & 0.009 & 0.008 & 0.074 \\
$3.0 \mathrm{Al}$ & 12.7 & 1.19 & 2.98 & 0.009 & 0.007 & 0.072 \\
$4.5 \mathrm{Al}$ & 12.6 & 1.18 & 4.47 & 0.008 & 0.006 & 0.063 \\
$6.0 \mathrm{Al}$ & 13.1 & 1.37 & 6.17 & 0.007 & 0.005 & 0.062 \\
\hline
\end{tabular}
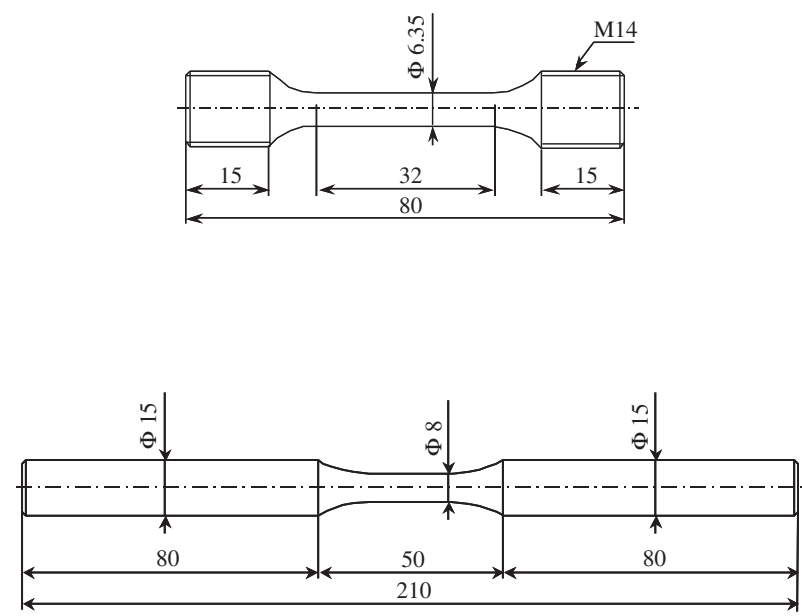

Fig. 1 The shapes and dimensions of tensile and fatigue testing specimens.

diameter round bars. The alloy marks and chemical compositions are shown in Table 1. All specimens were prepared from the hot-forged round bars by cutting, grinding and polishing. The shapes and dimensions of tensile and fatigue testing specimens are shown in Fig. 1. Once they were sealed into quartz tubes, all specimens were solution-treated at $1173 \mathrm{~K}$ for $3.6 \mathrm{ks}$ and then quenched in water by immersing the tubes in water and immediately breaking the tubes. The tensile and fatigue test samples were also solution-treated at 


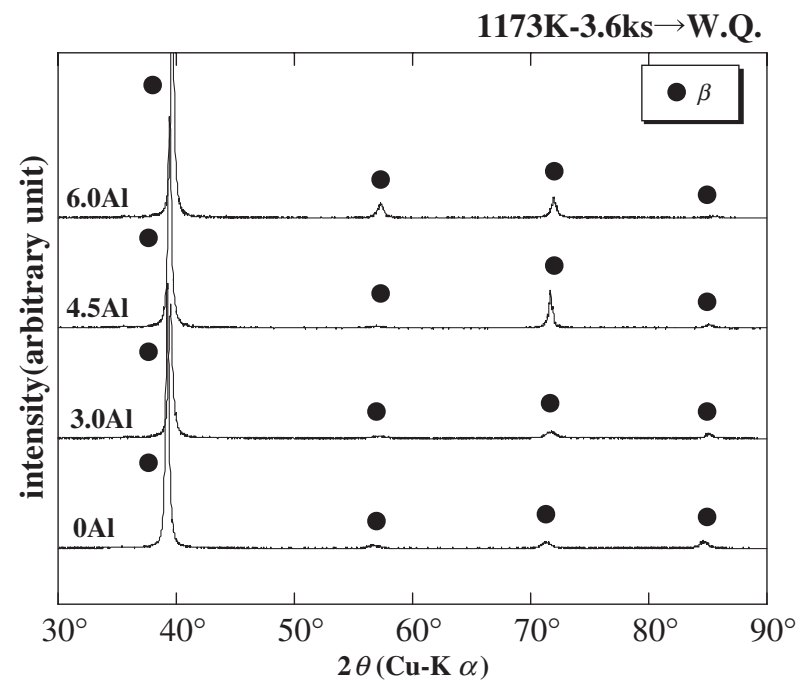

Fig. 2 X-ray diffraction profiles in the STQed state.

$1173 \mathrm{~K}$ for $3.6 \mathrm{ks}$ and then quenched in water. This solution treatment will hereafter be abbreviated as STQ. In STQed specimens, the electrical resistivity at room and liquid nitrogen temperatures $\left(\rho_{\mathrm{RT}}\right.$ and $\left.\rho_{\mathrm{LN}}\right)$ and Vickers hardness (HV) were measured. The phase constitution was identified by X-ray diffractometry (XRD). Microstructures were observed by optical microscopy. Tensile tests were performed at room temperature. The fatigue test was performed by rotating the bending-type fatigue testing machine at a rotation speed of $2600 \mathrm{rpm}$.

\section{Results and Discussion}

Figure 2 shows X-ray diffraction profiles in the STQed state. In all STQed specimens, XRD revealed only $\beta$ reflection. Figure 3 shows optical micrographs in the STQed state. A recrystallized structure was observed. The grain size of $0 \mathrm{Al}$ to $6.0 \mathrm{Al}$ was almost the same, i.e. about $300 \mu \mathrm{m}$.

Figure 4 shows the variation with $\mathrm{Al}$ content of the resistivity at room and liquid nitrogen temperatures $\left(\rho_{\mathrm{RT}}\right.$ and $\left.\rho_{\mathrm{LN}}\right)$, the resistivity ratio $\left(\rho_{\mathrm{LN}} / \rho_{\mathrm{RT}}\right)$, and the Vickers hardness (HV) in the STQed state. Resistivity at room and liquid nitrogen temperatures increased monotonically with $\mathrm{Al}$ content. These increases were due to the dissolution of $\mathrm{Al}$ in matrix. The resistivity at liquid nitrogen temperature was higher than that at room temperature. The resistivity ratios increased with increasing $\mathrm{Al}$ content up to 3.0 mass $\%$ and then decreased with increasing $\mathrm{Al}$ content. It was reported ${ }^{5)}$ that the selected area electron diffraction (SAED) patterns changed with increasing $\mathrm{Al}$ addition. According to the report, weak diffuse scattering reflections which were attributed to athermal $\omega$ were observed in Ti-13 mass $\% \mathrm{Cr}-1$ mass $\% \mathrm{Fe}$ and Ti-13 mass \% Cr-1 mass $\% \mathrm{Fe}-3$ mass $\% \mathrm{Al}$, and it didn't exist in Ti-13 mass $\% \mathrm{Cr}-1$ mass $\% \mathrm{Fe}-6$ mass $\% \mathrm{Al}$, higher $\mathrm{Al}$ content alloy. Those results imply that the volume fraction of athermal $\omega$ decreases with increasing $\alpha$ stabilizing elements, e.g. Al in the $\beta$ phase. Furthermore, it is thought that the reason the resistivity ratio of $\beta$ titanium alloys decreases is due to decrease of volume fraction of athermal $\omega^{6-8)}$ It is considered that athermal $\omega$ is not observed by XRD because

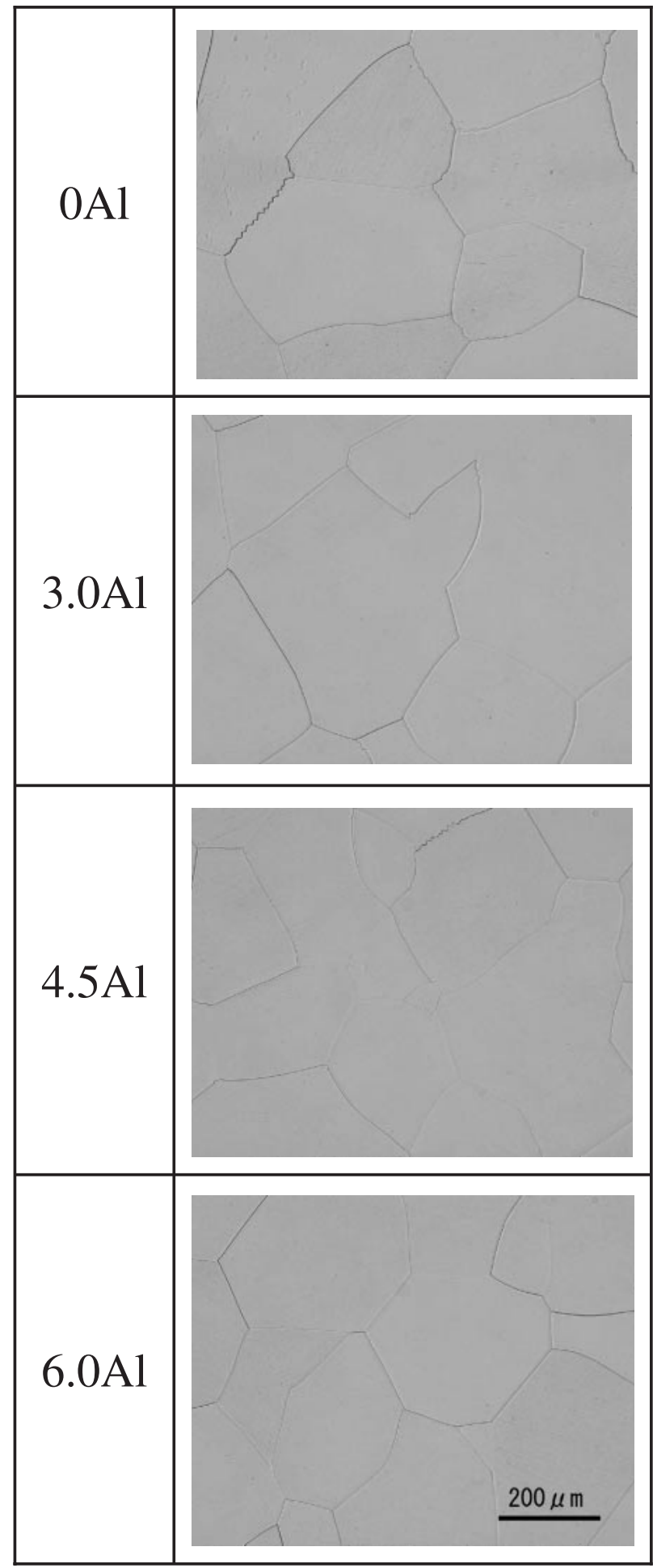

Fig. 3 Optical micrographs in the STQed state.

the volume fraction of athermal $\omega$ is too low to detect it. The same phenomenon is observed in Ti-V-Al alloys. ${ }^{6}$ ) It has been reported that with increasing $\mathrm{Al}$ addition, the starting temperature of athermal $\omega$ formation is lowered and the volume fraction of athermal $\omega$ at room temperature is reduced. ${ }^{6}$ Vickers hardness slightly increased with $\mathrm{Al}$ content up to 4.5 mass $\%$. In 6.0 mass $\% \mathrm{Al}$, the Vickers hardness increased dramatically. It is considered that cause of hardness change is due to change in balance between 




Fig. 4 The variation with $\mathrm{Al}$ content of the resistivity at room and liquid nitrogen temperatures $\left(\rho_{\mathrm{RT}}\right.$ and $\left.\rho_{\mathrm{LN}}\right)$, the resistivity ratio $\left(\rho_{\mathrm{LN}} / \rho_{\mathrm{RT}}\right)$ and the Vickers hardness (HV) in the STQed state.


Fig. 5 The variation with $\mathrm{Al}$ content of the tensile strength $\left(\sigma_{\mathrm{B}}\right), 0.2 \%$ proof stress $\left(\sigma_{0.2}\right)$, elongation $(\delta)$ and reduction in area $(\phi)$ in the STQed state.

decrease of hardness with decreasing of athermal $\omega$ and increasing of solution-hardening with $\mathrm{Al}$ addition. ${ }^{9)}$

Figure 5 shows the variation with $\mathrm{Al}$ content of the tensile strength $\left(\sigma_{\mathrm{B}}\right), 0.2 \%$ proof stress $\left(\sigma_{0.2}\right)$, elongation $(\delta)$ and



Fig. 6 SEM micrographs of fracture surfaces after tensile testing.

reduction in area $(\phi)$ in the STQed state. In $0 \mathrm{Al}$ and 3.0Al, $\sigma_{\mathrm{B}}$ and $\sigma_{0.2}$ remained almost constant. In the $0 \mathrm{Al}, \sigma_{\mathrm{B}}$ and $\sigma_{0.2}$ were roughly 930 and $900 \mathrm{MPa}$, respectively. The $\delta$ and $\phi$ of the $0 \mathrm{Al}$ were about $20 \%$ and $60 \%$, respectively. Above 4.5 mass $\%, \sigma_{\mathrm{B}}$ and $\sigma_{0.2}$ increased with $\mathrm{Al}$ content. The increase in both was due to the solution-hardening by Al. The $\delta$ and $\phi$ of both $0 \mathrm{Al}$ and 3.0Al remained almost constant up to 4.5Al. In the 6.0Al, $\sigma_{\mathrm{B}}$ and $\sigma_{0.2}$ increased slightly, while $\delta$ and $\phi$ decreased slightly. These alloys in STQed state show good balance between strength and ductility. For example, the $\sigma_{\mathrm{B}}$, $\delta$ and $\phi$ of Ti-22\% V-4\% Al, a commercial $\beta$ titanium alloy, are about $760 \mathrm{MPa}, 22 \%$ and $65 \% .{ }^{10)}$ Figure 6 shows SEM micrographs of fracture surfaces after tensile testing. Dim- 
ples were observed in all specimens. The fracture surfaces of these specimens were almost entirely covered with dimples whose shape and size hardly varied with alloy composition.

Figure 7 shows S-N curves of high cycle fatigue test. S-N curves of $0 \mathrm{Al}$ and 3.0Al exhibited almost the same behavior, and the fatigue limit of these alloys was almost the same value. Above 4.5 massAl\%, S-N curves slightly shifted toward low stress. To reveal cause of change of S-N curve, a further investigation about fatigue test is necessary. The stress at $10^{7}$ cycles, i.e. the fatigue strength of $0 \mathrm{Al}$, was around $460 \mathrm{MPa}$. For example, the stress at $10^{7}$ cycles of Ti$22 \% \mathrm{~V}-4 \% \mathrm{Al}$ alloy was reported to be around $300 \mathrm{MPa} .{ }^{11)}$ Figure 8 shows SEM micrographs of fracture surfaces of $0 \mathrm{Al}$ to $6.0 \mathrm{Al}$ after fatigue testing. The fatigue crack initiation site was observed at near surface. From Fig. 4, it is considered that volume fraction of athermal $\omega$ of $3.0 \mathrm{Al}$ is lower than that

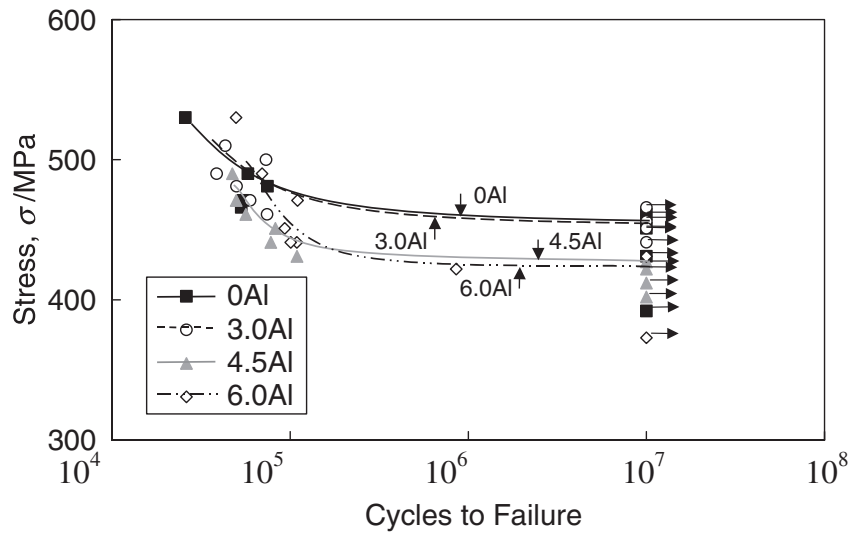

Fig. 7 S-N curves of high cycle fatigue test.

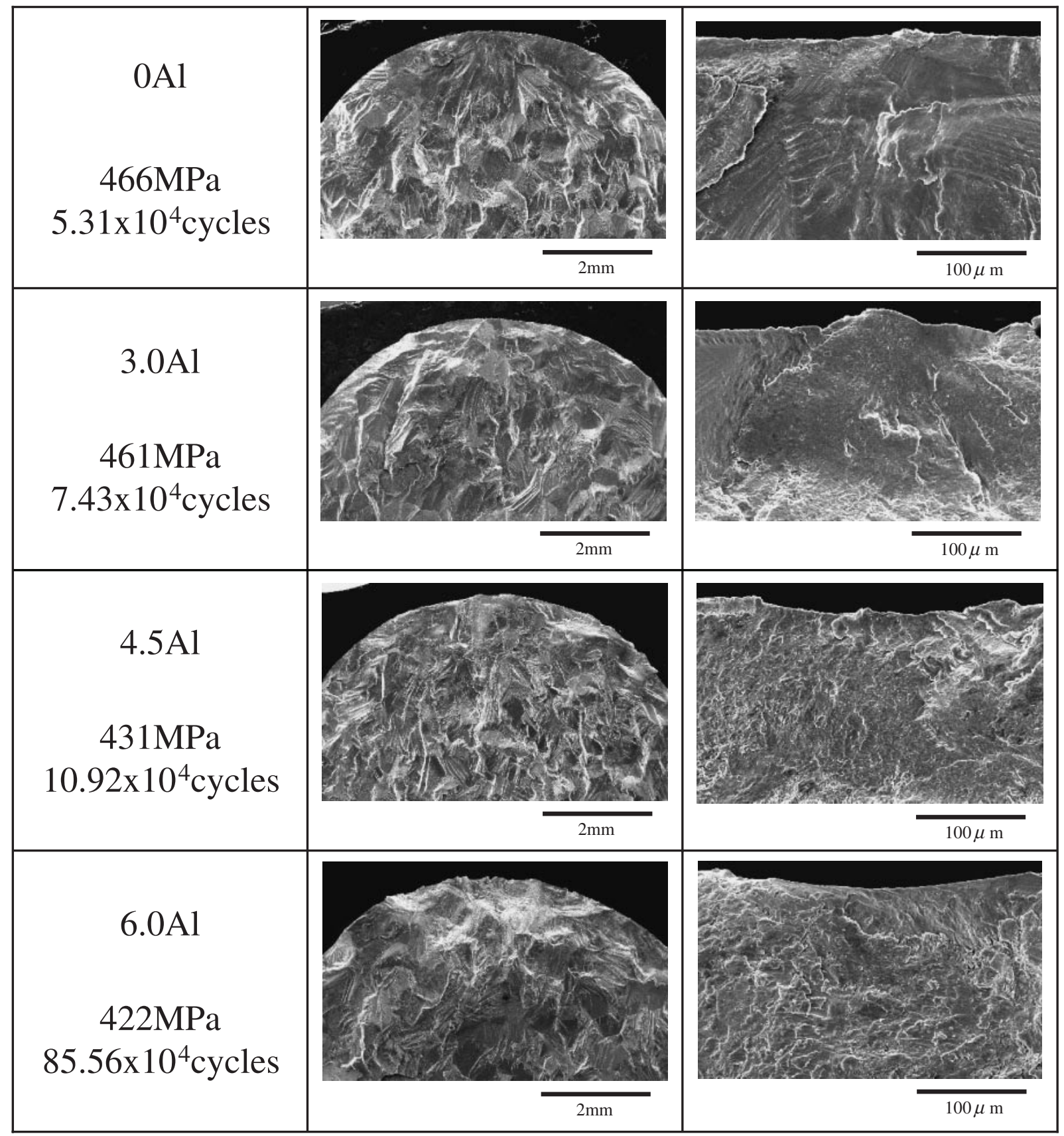

Fig. 8 SEM micrographs of fracture surfaces of $0 \mathrm{Al}$ to $6.0 \mathrm{Al}$ after fatigue testing. 
of 0Al. However, tensile and fatigue properties of 3.0Al were almost the same as those of 0Al. Thus, it is considered that athermal $\omega$ hardly influences the tensile and fatigue properties in alloys below 3.0Al.

\section{Conclusions}

The effect of $\mathrm{Al}$ content on tensile and fatigue properties of $\mathrm{Ti}-13 \mathrm{Cr}-1 \mathrm{Fe}$ alloys was investigated by measurement of electrical resistivity and Vickers hardness, X-ray diffractometry (XRD), and tensile and fatigue tests. Only $\beta$ reflection was detected by XRD in all alloys quenched from $1173 \mathrm{~K}$. Resistivity at room and liquid nitrogen temperatures increased monotonically with $\mathrm{Al}$ content. Vickers hardness slightly increased with $\mathrm{Al}$ content up to 4.5 mass \%. In 6.0 mass\% $\mathrm{Al}$, the Vickers hardness increased dramatically. In 0 mass $\% \mathrm{Al}$ and 3.0 mass $\% \mathrm{Al}$, the tensile strength $\left(\sigma_{\mathrm{B}}\right)$ and $0.2 \%$ proof stress $\left(\sigma_{0.2}\right)$ remained almost constant. Above 4.5 mass $\%, \sigma_{\mathrm{B}}$ and $\sigma_{0.2}$ increased with increasing $\mathrm{Al}$ content. S-N curves in high cycle fatigue test of 0 mass $\% \mathrm{Al}$ and 3.0 mass $\% \mathrm{Al}$ showed almost the same behavior. The stress at $10^{7}$ cycles, i.e. the fatigue strength, was around $460 \mathrm{MPa}$.

\section{REFERENCES}

1) Home Page of the Ministry of Health, Labour and Welfare of Japan: http://www.mhlw.go.jp.

2) M. Niinomi: Recent biocompatibility Metallic Materials, Structural Biomaterials for the 21st Century, ed. by M. Niinomi, T. Okabe, E. M. Taleff, D. R. Lesuer and H. E. Lippard, (TMS, Warrendale, 2001) pp. 3-14.

3) M. Ikeda, S. Komatsu, M. Ueda and K. Inoue: CAMP-ISIJ 14 (2001), 1340 .

4) A. W. Bowen: Scr. Meter. 5 (1971) 709-716.

5) M. Ogawa, T. Shimizu, T. Noda and M. Ikeda: J. Japan Inst. Metals 70 (2006) 359-364.

6) M. Ikeda, S. Komatsu, T. Sugimoto and K. Kamei: J. JILM 42 (1992) 622-626.

7) M. Ikeda, S. Komatsu, T. Sugimoto and K. Kamei: J. Japan Inst. Metals 54 (1990) 743-751.

8) J. C. Williams, B. S. Hickman and D. H. Leslie: Met. Trans. 2 (1971) 477-484.

9) M. Ikeda, S. Komatsu, T. Sugimoto, K. Kamei and K. inoue: Tetsu-toHagane 80 (1994) 866-870.

10) S. Fukui, Y. Ohtakara and A. Suzuki: Electric Furnace Steel 57 (1986) 303-317.

11) K. Tokaji, K. Ohya and H. Kariya: J. Soc. Mat. Sci., Japan 49 (2000) 994-1001. 